\title{
STUDY OF W-X BONDS IN AMORPHOUS W-B-C
}

\author{
1 Jaroslav ŽENÍŠEK, ${ }^{1}$ Pavel SOUČEK, ${ }^{1,2}$ Pavel ONDRAČKA, ${ }^{3}$ Petr VAŠINA
}

${ }^{1}$ Masaryk University, Faculty of Science, Brno, Czech Republic, EU, jzenisek@mail.muni.cz,soucek@mail.muni.cz,pavel.ondracka@gmail.com

2Materials Chemistry, RWTH Aachen University, Aachen, Germany, EU, ondracka@mch.rwth-aachen.de

${ }^{3}$ Masaryk University, Faculty of Science, Brno, Czech Republic, EU, vasina@physics.muni.cz

https://doi.org/10.37904/nanocon.2021.4380

\begin{abstract}
We examine the validity of assumptions commonly used for the analysis of bonds (bond fractions) in amorphous W-B-C systems by a deconvolution procedure applied on measured XPS profiles. We focus on the relationship between the chemical shift of $4 f$ electronic states of $W$ atoms and the relative amounts of $W$ $X$ bonds $(X=W, B, C)$. The bond fraction analysis of amorphous $W-B-C$ assumes that the formation of binary $\mathrm{W}-\mathrm{B}$ and $\mathrm{W}-\mathrm{C}$ bonds leads to a shift of $4 \mathrm{f}$ electron binding energies to lower and higher values, respectively, due to the differences in the Pauling electronegativity of W, B and C. Different W-B-C compositions also lead to different relative amounts of $\mathrm{W}-\mathrm{W}$ bonds but their effect on the chemical shift is usually neglected. To test these assumptions we generated amorphous W-B-C atomic model of W40B30C30 composition (atomic percent), calculated the $\mathrm{W} 4 \mathrm{f}$ core electron binding energies from ab initio methods and examined relationships between the $\mathrm{W}-\mathrm{X}$ bonds and the chemical shift of $4 \mathrm{f}$ electron binding energies. Our analysis confirms the expected chemical shifts in W-B-C caused by W-C bonds. Additionally, we found a correlation between W-W bonds and $\mathrm{W} 4 \mathrm{f}$ electronic states and discuss its influence on the bond fraction analysis.
\end{abstract}

Keywords: XPS, bonds, amorphous materials, atomistic model

\section{INTRODUCTION}

Amorphous WBC coatings were shown to be both hard and fracture resistant [1] which renders them as possible candidates for protection of cutting and forming tools. Previous studies, e.g. in [2,3], also correlated the mechanical properties with calculated bond fractions as determined from the analysis of X-ray Phototelectron Spectroscopy (XPS) measurements, specifically from the deconvolution of the W $4 \mathrm{f}$ spectra. This work discusses and reviews the assumptions so far commonly used in the XPS bonding analysis of amorphous W-B-C materials with different compositions. In the W-B-C systems, the formation of binary W-B and $\mathrm{W}-\mathrm{C}$ bonds leads to a shift in core-level energy to lower and higher binding energies, respectively, of $\mathrm{W}$ $4 \mathrm{f}$ core electrons due to the differences in the Pauling electronegativity of $\mathrm{W}, \mathrm{B}$ and $\mathrm{C}$.

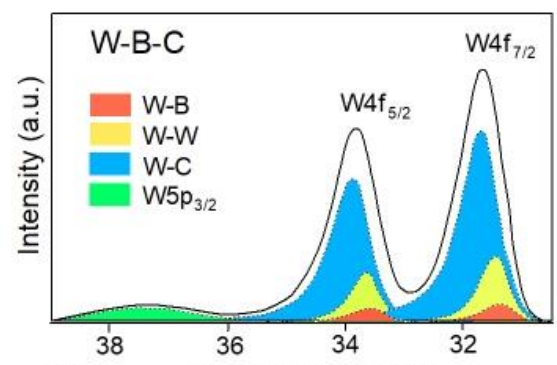

(a) Binding energy $(\mathrm{eV})$

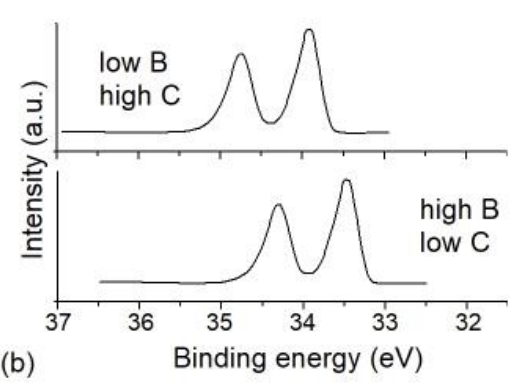

Figure 1 Schematically deconvolution of $\mathrm{W} 4 \mathrm{f}$ peaks to contributions due to $\mathrm{W}-\mathrm{X}$ bonds (a) and the effect of relative amounts of $B$ and $C$ atoms on chemical shift in $W-B-C$ materials (b) 
The bond analysis of the WBC systems based on the deconvolution of XPS W4f peaks (Figure 1(a)) is usually based on the assumption that W-C and W-B bonds present in the WBC systems shift the W $4 f$ peak position compared to the pure $\mathrm{W}$ (W-W bonds only). The $\mathrm{B}$ and $\mathrm{C}$ atoms should have an opposite (in direction, not in magnitude) effect on the peak position, as schematically depicted in Figure $\mathbf{1}(\mathrm{b})$. It is also assumed that the variation in the number of $\mathrm{W}-\mathrm{W}$ bonds does not change the peak position. To verify these presumptions, we generate an amorphous W-B-C atomistic model, calculate the $\mathrm{W} 4 \mathrm{f}$ core electron binding energies from $a b$ initio methods and examine the relationship between the $\mathrm{W} 4 \mathrm{f}$ electron binding energies and the amount of $\mathrm{W}$ $\mathrm{X}$ bonds in the local atomic configurations surrounding $\mathrm{W}$ atoms.

\section{ATOMISTIC MODELLING OF AMORPHOUS WBC}

\subsection{Ab initio methodology}

Density functional theory (DFT) $[4,5]$ was used to create W40B30C30 atomistic amorphous-like model and calculate the $\mathrm{W} 4 \mathrm{f}$ core electron binding energies. First, $40 \mathrm{~W}, 30 \mathrm{~B}$, and $30 \mathrm{C}$ atoms were randomly (with the constraint of keeping physically appropriate interatomic distances) placed in a starting cubic unit cell, with size corresponding to the mass density of $13 \mathrm{~g} / \mathrm{cm} 3$. That cell was used as a starting point for a "melt and quench" ab initio molecular dynamics (AIMD), where it was at first kept at $4000 \mathrm{~K}$ for 10002 fs steps, and then cooled to $300 \mathrm{~K}$ over $50002 \mathrm{fs} \mathrm{MD} \mathrm{steps.} \mathrm{The} \mathrm{temperature} \mathrm{was} \mathrm{controlled} \mathrm{with} \mathrm{the} \mathrm{Nosé-Hoover} \mathrm{thermostat} \mathrm{[6].} \mathrm{The}$ resulting structure was fully relaxed at $0 \mathrm{~K}$ with respect to the atomic positions, cell size and shape, so that the remaining forces on the atoms were smaller than $0.01 \mathrm{eV} / \AA$. The binding energies of electrons in states $4 \mathrm{f}_{5 / 2}$ were calculated for each W atom in the W-B-C model by the Slater's Transition State method [7] in which half of an electron is moved from the specific core level to the valence band and the binding energy is calculated as the difference between the energy eigenvalue of the state with the half-occupancy and a Fermi level. We used three different DFT codes in order to maintain optimal trade-off between speed and precision. AIMD was done with the OpenMX package using norm-conserving pseudopotentials [8], pseudo-atomic localized basis

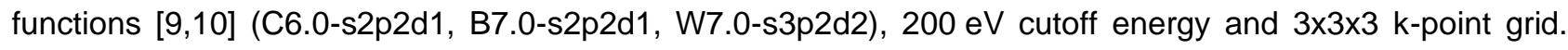
Structral relaxation at $0 \mathrm{~K}$ was done with the VASP code [11], PAW pseudopotentials [12,13], $500 \mathrm{eV}$ planewave energy cutoff, $0.2 \mathrm{eV}$ Gaussian smearing and a $4 \times 4 \times 4$ Monkhorst-Pack [14] $k$-point grid. For the calculation of W $4 f$ core electron binding energies we used all-electron full-potential Wien2k code [15]. The calculations were carried out with the basis set size parameter RKmax $=7$ and k-point grid of $4 \times 4 \times 4$. The $4 f$ states were modelled as core-states (for all atoms at least $98 \%$ of the corresponding $4 \mathrm{f}$ electronic charge around $\mathrm{W}$ atoms was inside the muffin-tin region). Core density superposition was done each self-consistent cycle. Muffin tin radii were set to almost touching spheres, corresponding to approximately 2.1, 1.4, 1.4 Bohr radii for W,B and C respectively. PBE exchange-correlation functional [16] was used for all calculations.

\subsection{Analysis of local environments of $\mathrm{W}$ atoms}

The $\mathrm{W}$ atoms are sorted by their $4 \mathrm{f}_{5 / 2}$ electron binding energies (from the lowest to the highest) and divided in groups corresponding to $0.2 \mathrm{eV}$ binding energy intervals. The number of atoms $\mathrm{X}$ within an interval of distances from $W$ is determined for each $W$ from a binding energy interval. An example of this is schematically depicted in Figure 2 for $B$ atoms within the distance interval (2.0-2.5) $\AA$ from $W$ atoms with $4 f_{5 / 2}$ electron binding energies from (34.0-34.2)eV interval. Figure 2(a) shows a structural model (unit cell) of an amorphous W-B-C system in which counting of the atomic neighbours to $\mathrm{W}$ atoms is performed. In this particular case, we have five $\mathrm{W}$ atoms whose $4 f_{5 / 2}$ electron binding energies are within the (34.0-34.2) $\mathrm{eV}$ interval. Figure 2(b) shows only those $W$ atoms together with their neighbouring $B$ atoms in the distance interval $(2.0-2.5) \AA$. We see that we have $(1+2+0+1+2)=6 \mathrm{~B}$ atoms, the volume of the shell specified by the radii of $2.0 \AA$ and $2.5 \AA$ is $32 \AA^{3}$ so the average number density is $6 /\left(5^{\star} 32\right)=0.04 \mathrm{~B}$ atoms per $\AA^{3}$. This value is shown with a gray column in Figure 2(c). The same procedure is then applied for $\mathrm{W}$ atoms from (34.2-34.4) eV and further intervals as indicated by the dashed columns in Figure 2(c). The average number densities of $W$ and $C$ in the selected 
distances from $W$ atoms grouped according to their $4 f_{5 / 2}$ electron binding energies are determined analogically. The identification of atoms surrounding $\mathrm{W}$ atoms is performed with the use of periodic boundary conditions. An example of this is marked with arrows in Figure 2(a) and (b). The B atom close to $W$ with $34.02 \mathrm{eV}$ in Figure 2(b) finds itself actually slightly below the bottom side of the unit cell. It is the periodic image of the $B$ atom inside unit cell marked with arrow in Figure 2(a).

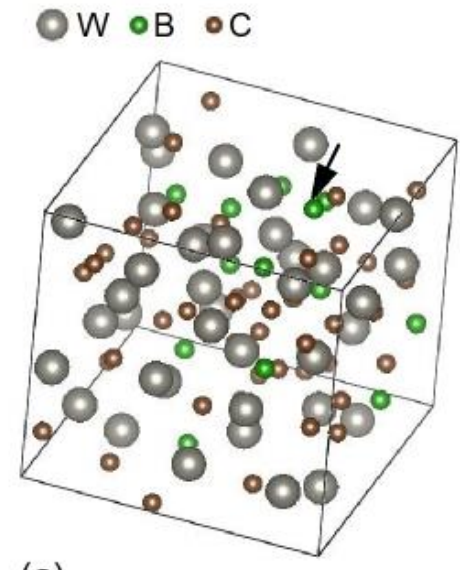

(a)

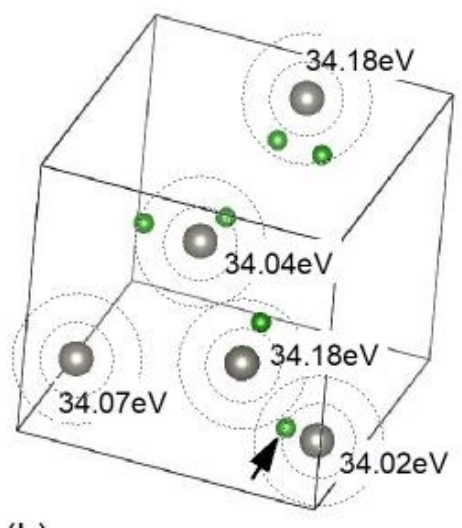

(b)

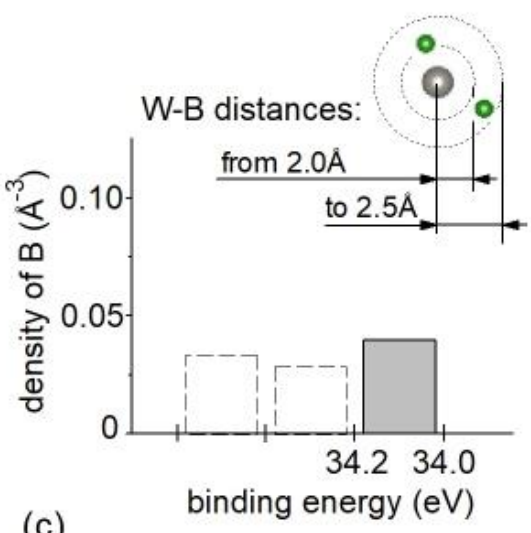

(c)

Figure 2 Analysis of the average number density of $B$ atoms within distances (2.0-2.5) $\AA$ from $W$ atoms whose $4 f_{5 / 2}$ electron binding energies are within (34.0-34.2) eV interval

The results of analysis described above are shown below as columnar plots. The analysis itself is similar to the determination of radial distribution function whose schematic example is depicted in the upper part of Figure 3. If the thickness of a shell specifying the examined zone around $W$ atoms goes to zero and the number density of atoms $X$ is evaluated for all shells centred at $W$ atoms together regardless of $W 4 f_{5 / 2}$ electron binding energies, then a point on radial distribution function is in principle obtained (other steps like normalizing are omitted now for simplicity). Some features of the columnar plots can be therefore predicted from the shape of a radial distribution function and this is shown in the bottom part of Figure 3. Shells too close to the central $\mathrm{W}$ atoms will be empty and no columns will be present in the plots.

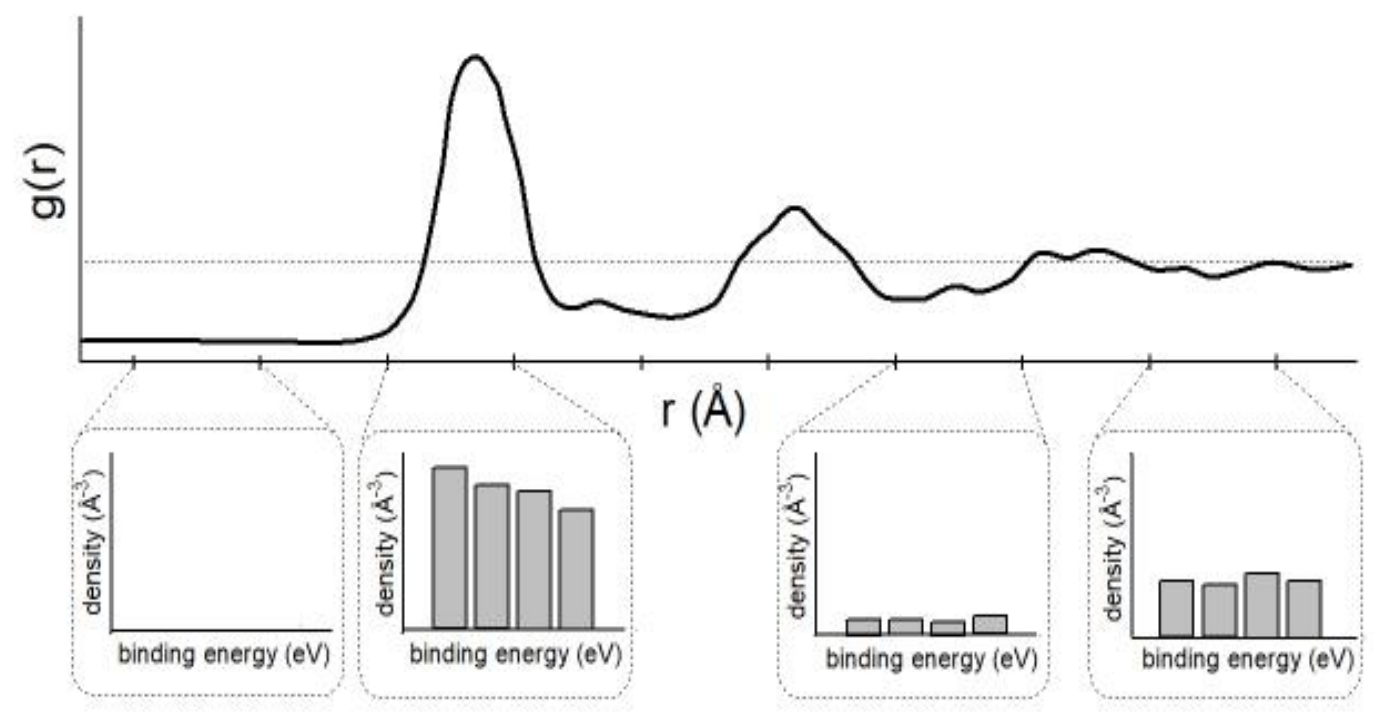

Figure 3 Expected relative column heights for different distance intervals of atoms $X$ from central $W$ atoms from comparison with a radial distribution function (schematic example) 
The closest atomic neighbours $\mathrm{X}$ to the $\mathrm{W}$ atoms form the first peak in the radial distribution function. Corresponding columnar plot should show relatively high columns. If there is any dependency between the local density of $X$ in the bonding distances to $W$ (relative amount of $W-X$ bonds) and the $W 4 f_{5 / 2}$ electron binding energies, then the column height in the plot should vary. When moving further away from the $\mathrm{W}-\mathrm{X}$ bonding distances, no correlation between the density of $X$ in the corresponding shell and the $W 4 f_{5 / 2}$ electron binding energies is expected anymore. Therefore, the column height within one plot should become equal (within some fluctuations) but some variations in the column height are possible for various $\mathrm{W}-\mathrm{X}$ distances.

\section{RESULTS}

Our analysis tests the dependency between local chemical composition near $W$ atoms and the $W 4 f_{5 / 2}$ electron binding energies. The vicinities of $\mathrm{W}$ atoms are evaluated inside selected concentric shells $0.5 \AA$ thick. Local composition in a shell is described by number densities of $\mathrm{W}, \mathrm{B}$, and $\mathrm{C}$ atoms. The number densities are given as functions of $W 4 f_{5 / 2}$ electron binding energies in Figure 4. Densities of $B$ and $C$ atoms are examined in the interval of distances (2.0-2.5) $\AA$ from $W$ atoms, densities of neighbouring $W$ atoms are examined in distances (2.5-3.0) $\AA$ from central $W$ atoms. These intervals of distances correspond approximately to the distances where $\mathrm{W}-\mathrm{X}$ bonds can form and consequently influence the $\mathrm{W} 4 \mathrm{f}_{5 / 2}$ electron binding energies. The upper limits of the distance intervals ( $2.5 \AA$ for $\mathrm{W}-\mathrm{B}$ and $\mathrm{W}-\mathrm{C}$ and $3.0 \AA$ for $\mathrm{W}-\mathrm{W})$ are reasonably close to the bonding distances estimated from the sum of the covalent radii of elements $W$ and $X$ [17].
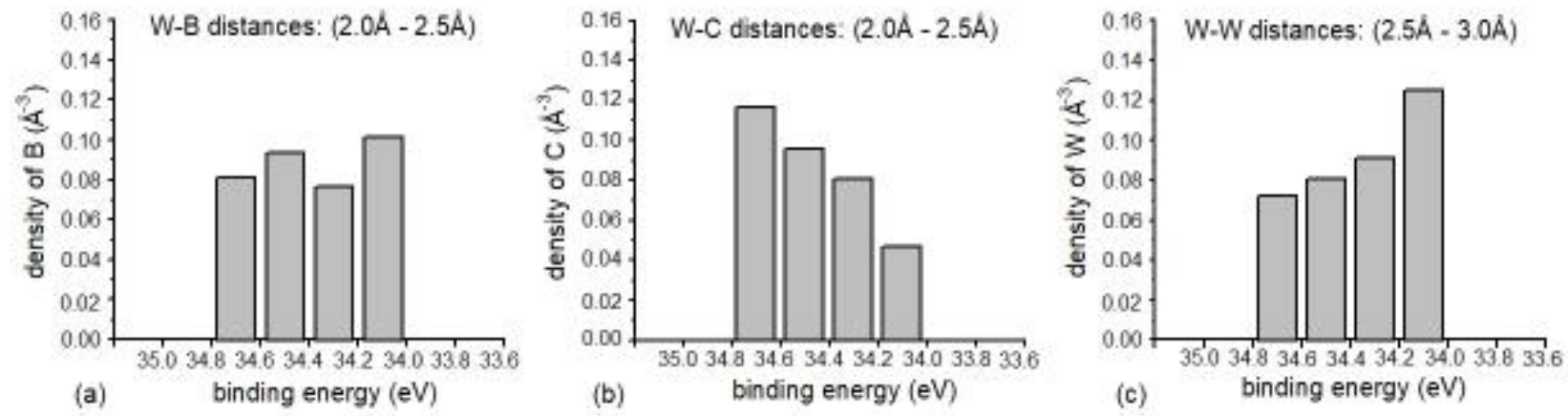

Figure 4 Relationships between the number densities of $\mathrm{W}, \mathrm{B}$, and $\mathrm{C}$ atoms near central $\mathrm{W}$ atoms and the $4 f_{5 / 2}$ electron binding energies of the central $W$ atoms

\section{DISCUSSION}

Plots from Figure $\mathbf{4}$ are used in Figure $\mathbf{5}$ where some remarks have been added to discuss the findings. Figure 5(a) shows that higher amount of $C$ in the bonding distances to $W$ shifts the $4 f_{5 / 2}$ electron binding energy to higher values. Shift in the opposite direction holds for lower $\mathrm{C}$ amounts. This is consistent with the assumption for the bond fraction analysis in W-B-C materials schematically depicted in Figure 1(b) in Introduction. The effect of $B$ shows an opposite trend than that of $C$, i.e., shift to higher binding energies with higher B density. However the effect is much weaker and exhibits some fluctuations, so while this is qualitatively consistent with the experimental bonding analysis assumptions, a larger dataset and/or analysis of more W-B-C compositions is needed for unequivocal validation.

The W-B-C bond fraction analysis (e.g. in [3]) neglects the effect of changing amount of W-W bonds on the chemical shift. If formation of $\mathrm{W}-\mathrm{W}$ bonds does not affect the $\mathrm{W} 4 \mathrm{f}_{5 / 2}$ electron binding energy, then an equal column height (marked by the dashed line in Figure $\mathbf{5}(\mathrm{b})$ ) would be expected. However, there is a clearly visible trend marked by the full line. This indicates that at lower $4 \mathrm{f}_{5 / 2}$ electron binding energies the $W$ atoms might be closely surrounded not only with the greater amount of $B$ relative to $C$ but also rather higher number of $\mathrm{W}$ atoms. This means that the shift to lower binding energies is not only due to forming a relatively higher 
amount of W-B, but also by forming more $\mathrm{W}-\mathrm{W}$ bonds. This is an important finding since if one assumes that changing the $\mathrm{W}$ concentration (and consequently the amount of $\mathrm{W}-\mathrm{W}$ bonds) in the $\mathrm{W}-\mathrm{B}-\mathrm{C}$ systems has no impact on the $\mathrm{W} 4 \mathrm{f}$ peak positions in the measured XPS profiles, then the deconvolution-based bond analysis might overestimate the $\mathrm{W}-\mathrm{B}$ bond fractions at the expense of $\mathrm{W}-\mathrm{W}$. Conversely, $\mathrm{W}$ 4f peaks shifted to the higher binding energies correspond to $W$ atoms surrounded by greater amount of $C$ atoms and lower amount of $B$ and also $W$ atoms. If one again assumes that changing of $W$ concentration in the W-B-C systems has no impact on the $\mathrm{W}$ 4f peak positions, then the deconvolution-based bond analysis might also underestimate the $\mathrm{W}-\mathrm{C}$ bond fractions in favour of W-W.
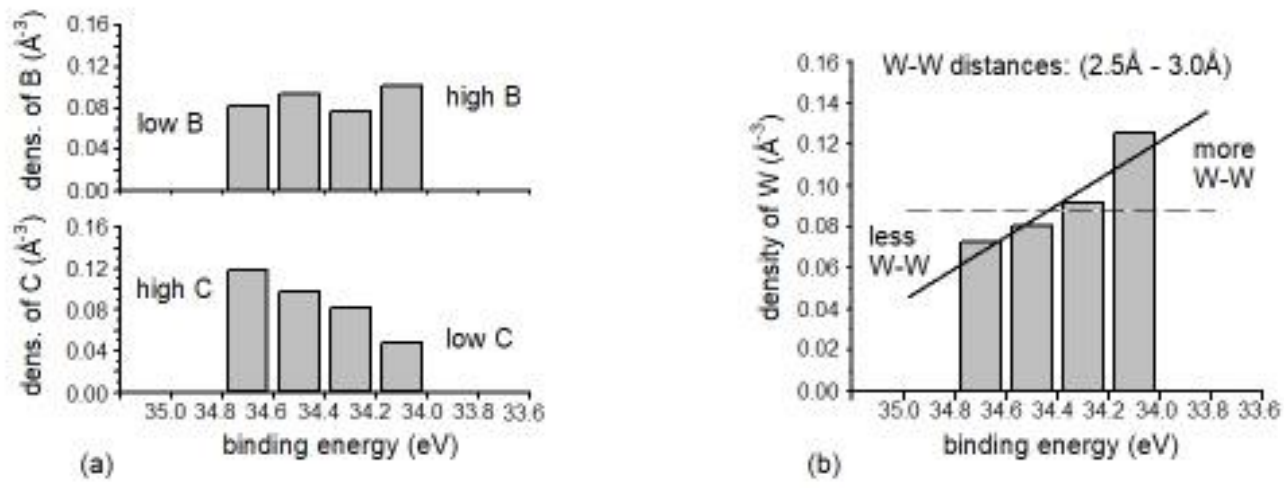

Figure 5 Verification of the expected effect of relative amounts of $B$ and $C$ atoms on chemical shift in W-B-C materials (a). Effect of varying density of $\mathrm{W}$ atoms in the bonding distances to the central $\mathrm{W}$ atoms on the $4 f_{5 / 2}$ electron binding energies of the central $W$ atoms $(b)$.

\section{CONCLUSION}

An atomistic model of amorphous W-B-C models was generated and used to analyze relationships between the local atomic environment of $W$ atoms and their $4 f_{5 / 2}$ electron binding energies. It was discovered that the W $4 \mathrm{f}$ binding energies depend not only on the local density of $\mathrm{C}$ atoms, and therefore $\mathrm{W}-\mathrm{C}$ bonds in the system (one of the assumptions commonly utilized in the bond fraction analysis) but also on the local density of $\mathrm{W}$ atoms (W-W bonds), which should be accounted for in future analyses.

\section{ACKNOWLEDGEMENTS}

This research has been supported by project LM2018097 funded by the Ministry of Education, Youth and Sports of the Czech Republic and project GA19-03899S financed by the Grant Agency of the Czech Republic. Computational resources were supplied by the project "e-Infrastruktura CZ" (eINFRA LM2018140) provided within the program Projects of Large Research, Development and Innovations Infrastructures and by JARA-HPC from RWTH Aachen University under project JARA0131.

\section{REFERENCES}

[1] ALISHAHI, M., MIRZAEI, S., SOUČEK, P., ZÁBRANSKY, L., BURŠÍKOVÁ, V., STUPAVSKÁ, M., PEŘINA, V., BALÁSZI, K., CZIGÁNI, Z., VAŠINA, P. Evolution of structure and mechanical properties of hard yet fracture resistant W-B-C coatings with varying B/W ratio. Surface and Coatings Technology. 2018, vol. 340, pp. 103-111.

[2] MIRZAEI, S., ALISHAHI, M., SOUČEK, P., ZÁBRANSKÝ, L., BURŠíKOVÁ, V., STUPAVSKÁ, M., PEŘINA, V., BALÁSZI, K., CZIGÁNI, Z., VAŠINA, P. Effect of bonding structure on hardness and fracture resistance of W-B-C coatings with varying B/W ratio. Surface and Coatings Technology. 2019, vol. 358, pp. 843-849. 
[3] MIRZAEI, S., ALISHAHI, M., SOUČEK, P., ŽENÍŠEK, J., HOLEC, D., KOUTNÁ, N., BURŠíKOVÁ, V., STUPAVSKÁ, M., ZÁBRANSKÝ, L., BURMEISTER, F., BLUG, B., CZIGÁNI, Z., BALÁSZI, K., MIKŠOVÁ, R., VAŠINA, P. The effect of chemical composition on the structure, chemistry and mechanical properties of magnetron sputtered W-B-C coatings: Modeling and experiments. Surface and Coatings Technology. 2020, vol. 383, pp. 125274-125284.

[4] HOHENBERG, P., KOHN, W. Inhomogeneous electron gas. Physical Review. 1964, vol. 136, pp. 864-871.

[5] KOHN, W., SHAM, L. J. Self-consistent equations including exchange and correlation effects. Physical Review. 1965, vol. 140, pp. 1133-1138.

[6] NOSÉ, S. A unified formulation of the constant temperature molecular dynamics methods. The Journal of Chemical Physics. 1984, vol. 81, pp. 511-519.

[7] SLATER, J.C. Statistical exchange-correlation in the self-consistent field. Advances in Quantum Chemistry. 1972, vol. 6, pp. 1-92.

[8] BLOECHL, P.E. Generalized separable potentials for electronic-structure calculations. Physical Review B. 1990, vol. 41, pp. 5414-5416.

[9] OZAKI, T. Variationally optimized atomic orbitals for large-scale electronic structures. Physical Review B. 2003, vol. 67, pp. 155108-155112.

[10] OZAKI, T., KINO, H. Numerical atomic basis orbitals from H to Kr. Physical Review B. 2004, vol. 69, pp. 195113195131.

[11] KRESSE, G., FURTHMUELLER, J. Efficient iterative schemes for ab initio total-energy calculations using a planewave basis set. Physical Review B. 1996, vol. 54, pp. 11169-11186.

[12] BLOECHL, P.E. Projector augmented-wave method. Physical Review B. 1994, vol. 50, pp. 17953-17979.

[13] KRESSE, G., JOUBERT, J. From ultrasoft pseudopotentials to the projector augmented wave method. Physical Review B. 1999, vol. 59, pp. 1758-1775.

[14] MONKHORST, H.J., PACK, J.D. Special points for Brillouin-zone integrations. Physical Review B. 1976, vol. 13, pp. 5188-5192.

[15] BLAHA, P., SCHWARZ, K., TRAN, F., LASKOWSKI, R., MADSEN, G.K.H., MARKS, L.D. WIEN2k: an APW+lo program for calculating the properties of solids. The Journal of Chemical Physics. 2020, vol. 152, pp. 074101-1 074101-30.

[16] PERDEW, J.P., BURKE, K., ERNZERNHOF, M. Generalized gradient approximation made simple. Physical Review Letters. 1996, vol. 77, pp. 3865-3868.

[17] CORDERO, B., GÓMEZ, V., PLATERO-PRATS, A.E., REVÉS, M., ECHEVERRÍA, J., CREMADES, E., BARRAGÁN, F., ALVAREZ, S. Covalent radii revisited. Dalton Transactions. 2008, issue 21, pp. 2832-2838. 